Case Report

\title{
A Case of Hyperacute Severe Thrombocytopenia Occurring Less than 24 Hours after Intravenous Tirofiban Infusion
}

\author{
Vineet Meghrajani $\mathbb{D}^{1},{ }^{1}$ Nitin Sabharwal, ${ }^{1}$ Vinod Namana $\mathbb{D}^{2},{ }^{2}$ Moustafa Elsheshtawy $\mathbb{D}^{2}$ \\ and Bernard Topi ${ }^{2}$ \\ ${ }^{1}$ Department of Internal Medicine, Maimonides Medical Center, 4802 10th Avenue, Brooklyn, NY 11219, USA \\ ${ }^{2}$ Department of Cardiology, Maimonides Medical Center, 4802 10th Avenue, Brooklyn, NY 11219, USA \\ Correspondence should be addressed to Vineet Meghrajani; vineetmeghrajani@gmail.com
}

Received 20 January 2018; Revised 24 March 2018; Accepted 10 May 2018; Published 24 May 2018

Academic Editor: Simon Davidson

Copyright (c) 2018 Vineet Meghrajani et al. This is an open access article distributed under the Creative Commons Attribution License, which permits unrestricted use, distribution, and reproduction in any medium, provided the original work is properly cited.

\begin{abstract}
Thrombocytopenia is defined as a condition where the platelet count is below the lower limit of normal $(<150 \mathrm{G} / \mathrm{L})$, and it is categorized as mild (100-149 G/L), moderate $(50-99 \mathrm{G} / \mathrm{L})$, and severe $(<50 \mathrm{G} / \mathrm{L})$. We present here a 79 -year-old man who developed severe thrombocytopenia with a platelet count of $6 \mathrm{G} / \mathrm{L}$, less than 24 hours after intravenous tirofiban infusion that was given to the patient during a percutaneous transluminal coronary angioplasty procedure with placement of 3 drug-eluting stents. The patient's baseline platelet count was $233 \mathrm{G} / \mathrm{L}$ before the procedure. Based on the timeline of events during hospitalization and laboratory evidence, it was highly likely that the patient's thrombocytopenia was the result of tirofibaninduced immune thrombocytopenia, a type of drug-induced immune thrombocytopenia (DITP) which occurs due to drugdependent antibody-mediated platelet destruction. Anticoagulant-mediated artefactual pseudothrombocytopenia was ruled out as no platelet clumping was seen on the peripheral blood smears. The treatment of DITP includes discontinuation of the causative drug; monitoring of platelet count recovery; or treatment of severe thrombocytopenia with glucocorticoids, IVIG, or platelet transfusions depending on the clinical presentation. The most likely causative agent of this patient's thrombocytopenia-tirofiban - was discontinued, and the patient did not develop any signs of bleeding during the remainder of his hospital stay. His platelet count gradually improved to $24 \mathrm{G} / \mathrm{L}$, and he was discharged on the sixth hospital day.
\end{abstract}

\section{Case}

A 79-year-old independently functioning man presented to the emergency room with an episode of substernal chest pain. His medical history included stable coronary artery disease, chronic systolic congestive heart failure with a left ventricular ejection fraction of $25 \%$, paroxysmal atrial fibrillation, type 2 diabetes mellitus, hyperlipidemia, and hypertension. The patient also had a cardiac resynchronization therapy defibrillator (CRT-D) device in place for 5 years. He described the chest pain as a sensation of substernal crushing that started when he was resting comfortably at home. The pain was moderate in intensity, nonradiating, and lasted for approximately 10 minutes before resolving spontaneously. He denied any dyspnea, palpitations, dizziness, or loss of consciousness during this episode. He had never smoked before. His home medications included aspirin $81 \mathrm{mg}$ daily, losartan $50 \mathrm{mg}$ daily, carvedilol $6.25 \mathrm{mg}$ twice daily, apixaban $5 \mathrm{mg}$ twice daily, and furosemide $40 \mathrm{mg}$ daily. On arrival in the emergency room, the patient was asymptomatic and hemodynamically stable. Electrocardiogram showed a paced cardiac rhythm with no acute ST segment or T wave changes. Laboratory workup sent on arrival to the ER included a complete blood count and coagulation profile with the following results: white blood cell count of $8.0 \mathrm{G} / \mathrm{L}$, hemoglobin level of $14.2 \mathrm{~g} / \mathrm{dl}$, and platelet count of $232 \mathrm{G} / \mathrm{L}$. The patient had an initial cardiac troponin level of 0.06 and a B-type natriuretic peptide level of $190 \mathrm{pg} / \mathrm{ml}$. Follow-up cardiac troponin levels were $0.06 \mathrm{ng} / \mathrm{ml}$ and $0.05 \mathrm{ng} / \mathrm{ml}$, respectively. Based on this 
presentation, it was decided to admit the patient to the telemetry floor for a possible NSTEMI with a TIMI score of 5 , and treatment was initiated with intravenous unfractionated heparin drip at 12 units/kg/hour. Monitoring of the aPTT was done every 6 hours for a total of 12 hours after initiation of heparin drip and once daily thereafter, to target the dosing of heparin. Therapeutic anticoagulation levels of aPTTs (between 52.0 and 79.9 seconds) were achieved throughout the duration of treatment with heparin drip. The patient's apixaban was held. A persantine thallium cardiac stress test was ordered, which showed moderate inferoapical left ventricular wall ischemia and inferior wall defect. The patient was subsequently planned for an elective coronary angiogram, which showed $80 \%-90 \%$ stenoses of the middle, distal, and second diagonal segments of the left anterior descending coronary artery with no acute coronary artery occlusions. The patient underwent placement of 3 drugeluting stents in the stenotic coronary segments during the procedure, received aspirin $325 \mathrm{mg}$, clopidogrel $600 \mathrm{mg}$ orally, and a bolus dose of tirofiban $(5 \mathrm{mg} / 100 \mathrm{ml}) 42.5 \mathrm{ml}$ intravenously and later the same day, was started on a tirofiban drip at a maintenance infusion rate of $0.15 \mathrm{mcg} /$ $\mathrm{kg} / \mathrm{min}$ for 3 hours. Used with PCI, glycoprotein (GP) IIb/IIIa inhibitors like tirofiban and abciximab have been shown to reduce the rates of death, myocardial infarction, and urgent target-vessel revascularization in patients with STEMI and NSTEMI. It was estimated that the patient had received a total of $89.5 \mathrm{ml}$ ( $4.5 \mathrm{mg}$ ) of tirofiban intravenously on the day of the coronary angiogram including the bolus dose and the maintenance dose. The patient's platelet count on the automated complete blood count test (CBC) drawn at 7.52 am on the day of the coronary angiogram was $233 \mathrm{G} / \mathrm{L}$, which dropped to $6 \mathrm{G} / \mathrm{L}$ on the automated $\mathrm{CBC}$ drawn at $6.53 \mathrm{am}$ the day after the procedure. A repeat $\mathrm{CBC}$ was ordered at $11.50 \mathrm{am}$ after the result of the first $\mathrm{CBC}$ drawn earlier during the day was reported, and it showed a platelet count of $10 \mathrm{G} / \mathrm{L}$ (Table 1 ). The CBC tests were run on blood collected from the patient in specimen tubes containing EDTA as an anticoagulant. The automated CBC tests were processed by using Beckman Coulter model LH 780 hematology blood analyzer, with the machine set to flag a result if the platelet count on a specimen was less than $50 \mathrm{G} / \mathrm{L}$. The automated CBC tests did not have any flags reported on the analyzer for platelet clumping in all the CBC tests performed on the patient's blood. A platelet count was subsequently done by visual inspection of a hematological smear of the blood specimens under microscope, which confirmed the result of the automated $\mathrm{CBC}$ and did not show any platelet clumping (Figure 1).

The patient did not have any signs of bleeding, including ecchymosis, bruises, hematuria, or blood in stool. He was subsequently admitted to the cardiac intensive care unit for further monitoring and all anticoagulation was held. Dual antiplatelet therapy with aspirin and clopidogrel was however continued, considering that he had recently undergone percutaneous coronary intervention with placement of drug-eluting stents and was therefore at a high risk of stent thrombosis. Another CBC drawn at $7.52 \mathrm{pm}$ the same day showed improvement in the platelet count to $19 \mathrm{G} / \mathrm{L}$.
TABLE 1: Results of the automated complete blood count tests.

\begin{tabular}{lccc}
\hline Date, time & $\begin{array}{c}\text { Platelet } \\
\text { count }(\mathrm{G} / \mathrm{L})\end{array}$ & $\begin{array}{c}\text { WBC } \\
\text { count }(\mathrm{G} / \mathrm{L})\end{array}$ & $\mathrm{Hb}(\mathrm{g} / \mathrm{dl}) / \mathrm{Hct}(\%)$ \\
\hline $8 / 5 / 17,1.54 \mathrm{pm}$ & 232 & 8 & $14.2 / 41.8$ \\
$8 / 6 / 17,7.32 \mathrm{am}$ & 195 & 6.3 & $13.0 / 38.1$ \\
$8 / 7 / 17,7.52 \mathrm{am}$ & 233 & 7.9 & $13.9 / 41.4$ \\
$8 / 8 / 17,6.53 \mathrm{am}$ & 6 & 10.5 & $11.3 / 32.8$ \\
$8 / 8 / 17,11.50 \mathrm{am}$ & 10 & 10.6 & $12.1 / 36.2$ \\
$8 / 8 / 17,7.52 \mathrm{pm}$ & 19 & 8.6 & $11.5 / 33.9$ \\
$8 / 9 / 17,5.00 \mathrm{am}$ & 24 & 9.3 & $11.4 / 33.9$ \\
\hline
\end{tabular}

WBC: white blood cell; Hb: hemoglobin; Hct: hematocrit.

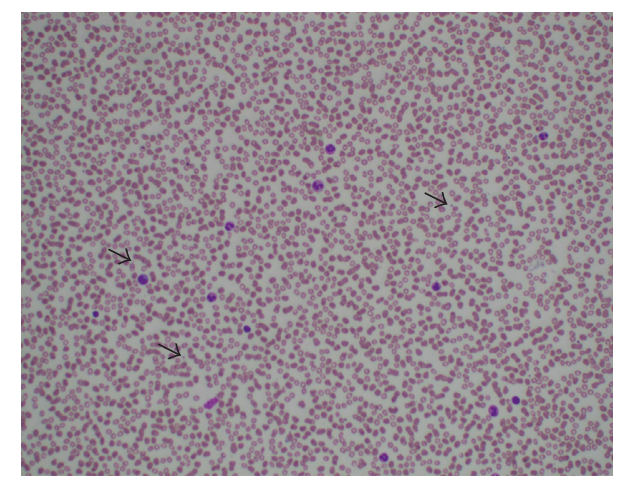

FIgURE 1: A Wright-Giemsa stained peripheral blood film of the patient under 200x microscopic magnification showing absence of platelet clumping. Scattered platelets are seen next to blue arrows with no clumping.

The patient did not develop any signs of bleeding during the remainder of his hospital stay, and his platelet count gradually improved to $24 \mathrm{G} / \mathrm{L}$ (Figure 2) before he was discharged on the sixth hospital day on aspirin and clopidogrel. The patient was provided outpatient follow-up with a plan to eventually resume anticoagulation with apixaban for paroxysmal atrial fibrillation once his platelet count had recovered to stable levels.

\section{Discussion}

Thrombocytopenia is defined as a condition where the platelet count is below the lower limit of normal $(<150 \mathrm{G} / \mathrm{L})$, and it is categorized as mild (100-149 G/L), moderate (50-99G/L), and severe $(<50 \mathrm{G} / \mathrm{L})$ [1]. The primary differential diagnoses in consideration for this patient's unexplained thrombocytopenia included pseudothrombocyt-openia, heparin-induced thrombocytopenia, and GP IIb/IIIa inhibitor- (tirofiban-) induced immune thrombocytopenia. Pseudothrombocytopenia is a term used to describe a falsely low-platelet count occurring due to a laboratory artifact, in which the anticoagulant EDTA used in specimen tubes may induce platelet clumping resulting in an artificially low-platelet count [2]. Pseudothrombocytopenia can be ruled out by visual inspection of the peripheral blood smear under microscope to check for platelet clumping and repeating the platelet count, both of which were done for our patient, with no 


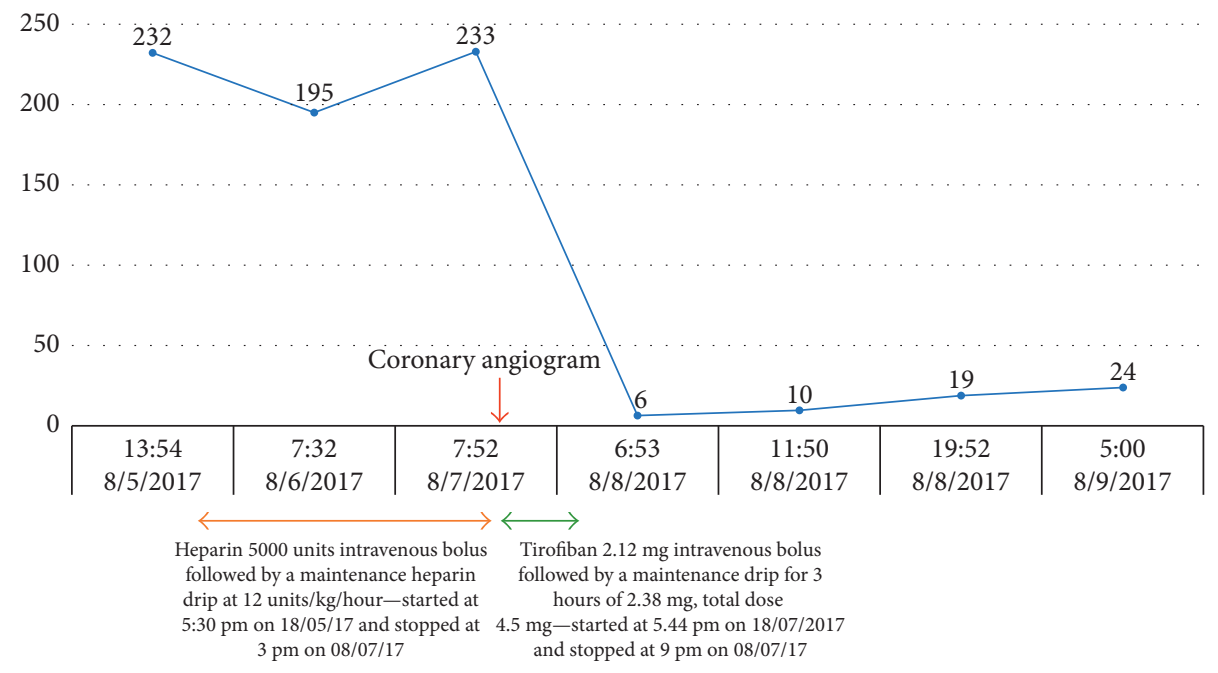

Figure 2: Platelet count in G/L over time with relation to drug exposure.

TABLe 2: The 4Ts score is the sum of the values for each of the 4 categories.

\begin{tabular}{|c|c|c|c|}
\hline \multicolumn{4}{|c|}{ The 4Ts scoring system } \\
\hline 4Ts category & 2 points & 1 point & 0 points \\
\hline Thrombocytopenia & $\begin{array}{c}\text { Platelet count fall }>50 \% \text { and platelet } \\
\text { nadir } \geq 20\end{array}$ & $\begin{array}{c}\text { Platelet count } 30 \%-50 \% \text { or platelet } \\
\text { nadir } 10-19\end{array}$ & $\begin{array}{c}\text { Platelet count fall }<30 \% \text { or } \\
\text { platelet nadir }<10\end{array}$ \\
\hline $\begin{array}{l}\text { Timing of platelet count } \\
\text { fall }\end{array}$ & $\begin{array}{l}\text { Clear onset days } 5-10 \text { or platelet fall } \\
\leq 1 \text { day (prior heparin exposure } \\
\text { within } 30 \text { days) }\end{array}$ & $\begin{array}{l}\text { Consistent with days } 5-10 \text { fall, but } \\
\text { not clear (e.g., missing platelet } \\
\text { counts); onset after day } 10 \text {; or fall } \leq 1 \\
\text { day (prior heparin exposure } 30-100 \\
\text { days ago) }\end{array}$ & $\begin{array}{c}\text { Platelet count } \leq 4 \text { days without } \\
\text { recent exposure }\end{array}$ \\
\hline $\begin{array}{l}\text { Thrombosis or other } \\
\text { sequelae }\end{array}$ & $\begin{array}{l}\text { New thrombosis (confirmed); skin } \\
\text { necrosis; acute systemic reaction } \\
\text { postintravenous unfractionated } \\
\text { heparin bolus }\end{array}$ & $\begin{array}{l}\text { Progressive or recurrent thrombosis; } \\
\text { nonnecrotizing (erythematous) skin } \\
\text { lesions; suspected thrombosis (not } \\
\text { proven) }\end{array}$ & None \\
\hline $\begin{array}{l}\text { Other causes of } \\
\text { thrombocytopenia }\end{array}$ & None apparent & Possible & Definite \\
\hline
\end{tabular}

Scores of $1-3,4-5$, and $6-8$ are considered to correspond to a low $(<5 \%)$, intermediate $(\sim 14 \%)$, and high $(\sim 64 \%)$ probability of HIT, respectively.

clumping seen on the peripheral smear and a platelet count that remained low on a subsequently drawn CBC. Heparininduced thrombocytopenia (HIT) is caused by autoantibodies to platelet factor 4 (PF4) complexed with heparin, which in turn activate platelets and cause widespread arterial and venous thrombosis and thrombocytopenia [3-6]. The "4Ts score" is a pretest scoring system for HIT that was developed to improve and standardize clinical diagnosis of heparin-induced thrombocytopenia [7-9] (Table 2). Although the patient had been receiving intravenous unfractioned heparin less than 24 hours before the drop in the platelet count, his 4 Ts score was calculated to be 1 , indicating that the probability of the patient having heparin-induced thrombocytopenia (HIT) was low (less than $5 \%$ ). He had not received heparin in the 100 days prior to this hospitalization.

Based on the clinical presentation, the timeline of events during hospitalization and laboratory evidence, it was highly likely that the patient's thrombocytopenia was the result of tirofiban-induced immune thrombocytopenia, as evidenced by its rapid onset ( $<24$ hours), and improvement in platelet count within a day of discontinuation of tirofiban. Glycoprotein IIb/IIIa receptor antagonists, including abciximab, eptifibatide, and tirofiban, are a class of antiplatelet medications that reduce platelet aggregation and thrombus formation through the blockade of key binding sites needed to stabilize the forming platelet aggregate [10]. Tirofiban is a small molecule reversible, competitive inhibitor of GP IIb/IIIa receptors that recognizes the arginine-glycineaspartic acid- (RGD-) binding sequence in the $\beta 3$ subunit of the GP IIb/IIIa receptor and binds within the ligandbinding pocket of the receptor to compete with fibrinogen, vWF, and other ligands resulting in inhibition of thrombi formation $[11,12]$. GP IIb/IIIa antagonists are widely used in the management of patients with acute coronary syndromes and patients undergoing coronary artery stenting due to their effects of preventing platelet aggregation and thrombus formation [13]. Used with PCI, glycoprotein (GP) IIb/IIIa inhibitors have been shown to reduce the rates of death, myocardial infarction, and urgent 
target-vessel revascularization in patients with STEMI and NSTEMI [14]. A documented side effect of GP IIb/IIIa inhibitors is thrombocytopenia, the incidence of which is reported to be higher in those receiving abciximab compared to eptifibatide or tirofiban [15-26]. Thrombocytopenia occurring secondary to GP IIb/IIIa inhibitors is included in a category of thrombocytopenia called drug-induced immune thrombocytopenia (DITP) which occurs due to drugdependent antibody-mediated platelet destruction [27, 28]. Drugs most commonly known to cause DITP include quinine, quinidine, trimethoprim-sulfamethoxazole, vancomycin, penicillin, rifampin, carbamazepine, ceftriaxone, ibuprofen, mirtazapine, oxaliplatin, suramin, GP IIb/IIIa inhibitors, and heparin (a comprehensive list can be obtained at http://www.ouhsc. edu/platelets/) $[29,30]$. There are various mechanisms by which these drugs cause DITP, with the mechanism depending on the type of drug causing it. Drugs like quinine and various antibiotics act by binding to the complementarity-determining region (CDR) of the antibody and modify it so that it acquires the ability to bind to a platelet glycoprotein, usually GP $\mathrm{Ib} / \mathrm{IX}$ or GP IIb/IIIa. These antibodies may (before affinity maturation) be derived from naturally occurring immunoglobulins that, in the absence of drug, bind very weakly to these targets and are clinically insignificant [31-33]. Abciximabdependent antibodies appear to recognize mouse-derived protein elements present in the mostly humanized Fab drug or conformational epitopes (neoepitopes) induced in the abciximab molecule when it binds to GP IIb/IIIa [18]. Ligandmimetic GP IIb/IIIa inhibitors like tirofiban and eptifibatide recognize neoepitopes induced in the GP IIb/IIIa head structure when these drugs react with the RGD recognition site and greatly increase the affinity of these antibodies for binding to platelet surface antigens by inducing structural changes in the GP IIb/IIIa receptor, thereby accelerating their destruction. Such antibodies may be naturally occurring, which may explain the observation of extremely rapid platelet count drop with GP IIb/IIIa inhibitors [15, 32, 34-37]. DITP is reversible upon drug discontinuation, with the platelet count expected to increase within one to two days of drug discontinuation and return to the patient's normal range in about seven to eight days $[30,38,39]$.

\section{Conclusion}

Immune thrombocytopenia occurring as a response to GP $\mathrm{IIb} / \mathrm{III}$ inhibitors is well documented in the existing literature, including multiple studies and case reports [40-49] and is diagnosed clinically by excluding other causes of thrombocytopenia and documenting resolution of thrombocytopenia upon drug discontinuation. This adverse effect resulting from tirofiban and other GP IIB/IIIa inhibitors is particularly concerning, considering how widely they are used in modern cardiovascular medicine practice for treatment of NSTEMIs and during percutaneous coronary interventions. Life-threatening complications such as alveolar and gastrointestinal system hemorrhages may occur in the course of thrombocytopenia [50]. DITP resulting from GP IIb/IIIa inhibitors puts these patients at an added risk due to these complications, which is in turn compounded due to the effects of the many antiplatelet drugs used in concurrence with GP IIb/IIIa inhibitors. The treatment of DITP includes discontinuation of the causative drug; monitoring of platelet count recovery; or treatment of severe thrombocytopenia with glucocorticoids, IVIG, or platelet transfusions depending on the clinical presentation [27].

\section{Conflicts of Interest}

The authors declare that they have no conflicts of interest.

\section{Acknowledgments}

Special thanks are due to Dr. Omar Azar, an attending pathologist at Maimonides Medical Center, for his contribution in analysis of the hematology slides.

\section{References}

[1] D. R. Williamson, M. Albert, D. Heels-Ansdell et al., "PROTECT collaborators, Canadian Critical Care Trials Group, Australian and New Zealand Intensive Care Society Clinical Trials Group. Thrombocytopenia in critically ill patients receiving thromboprophylaxis: frequency, risk factors, and outcomes," Chest, vol. 144, no. 4, pp. 1207-1215, 2013.

[2] A. Vicari, G. Banfi, and P. A. Bonini, "EDTA-dependent pseudothrombocytopaenia: a 12-month epidemiological study," Scandinavian Journal of Clinical and Laboratory Investigatio, vol. 48, no. 6, pp. 537-542, 1988.

[3] G. P. Visentin, S. E. Ford, J. P. Scott, and R. H. Aster, "Antibodies from patients with heparin-induced thrombocytopenia/ thrombosis are specific for platelet factor 4 complexed with heparin or bound to endothelial cells," Journal of Clinical Investigation, vol. 93, no. 1, pp. 81-88, 1994.

[4] T. E. Warkentin, C. P. Hayward, L. K. Boshkov et al., "Sera from patients with heparin-induced thrombocytopenia generate platelet-derived microparticles with procoagulant activity: an explanation for the thrombotic complications of heparin-induced thrombocytopenia," Blood, vol. 84, no. 11, pp. 3691-3699, 1994.

[5] M. Blank, Y. Shoenfeld, S. Tavor et al., "Anti-platelet factor 4/ heparin antibodies from patients with heparin-induced thrombocytopenia provoke direct activation of microvascular endothelial cells," International Immunology, vol. 14, no. 2, pp. 121-129, 2002.

[6] D. B. Cines, A. Tomaski, and S. Tannenbaum, "Immune endothelial-cell injury in heparin-associated thrombocytopenia," New England Journal of Medicine, vol. 316, no. 10, pp. 581-589, 1987.

[7] T. E. Warkentin and A. Greinacher, "Heparin-induced thrombocytopenia: recognition, treatment, and prevention: the seventh ACCP conference on antithrombotic and thrombolytic therapy," Chest, vol. 126, no. 3, pp. 311S-337S, 2004.

[8] A. Cuker, P. A. Gimotty, M. A. Crowther, and T. E. Warkentin, "Predictive value of the 4Ts scoring system for heparin-induced thrombocytopenia: a systematic review and meta-analysis," Blood, vol. 120, no. 20, pp. 4160-4167, 2012.

[9] G. K. Lo, D. Juhl, T. E. Warkentin, C. S. Sigouin, P. Eichler, and A. Greinacher, "Evaluation of pretest clinical score (4 Ts) for the diagnosis of heparin-induced thrombocytopenia in 
two clinical settings," Journal of Thrombosis and Haemostasis, vol. 4, no. 4, pp. 759-765, 2006.

[10] M. Hashemzadeh, M. Furukawa, S. Goldsberry, and M. R. Movahed, "Chemical structures and mode of action of intravenous glycoprotein IIb/IIIa receptor blockers: a review," Experimental and Clinical Cardiology, vol. 13, no. 4, pp. 192-197, 2008.

[11] K. Schrör and A. Weber, "Comparative pharmacology of GP IIb/IIIa antagonists," Journal of Thrombosis and Thrombolysis, vol. 15, no. 2, pp. 71-80, 2003.

[12] E. J. Topol, T. Byzova, and E. Plow, "Platelet GP IIb/IIIa blockers," The Lancet, vol. 353, no. 9148, pp. 227-231, 1999.

[13] S. Goto, N. Tamura, M. Li et al., "Different effects of various anti-GPIIb-IIIa agents on shear-induced platelet activation and expression of procoagulant activity," Journal of Thrombosis and Haemostasis, vol. 1, no. 9, pp. 2022-2030, 2003.

[14] C. Bode and K. Huber, "Antiplatelet therapy in percutaneous coronary intervention," European Heart Journal Supplements, vol. 10, pp. A13-A20, 2008.

[15] D. W. Bougie, P. R. Wilker, E. D. Wuitschick et al., "Acute thrombocytopenia after treatment with tirofiban or eptifibatide is associated with antibodies specific for ligandoccupied GPIIb/IIIa," Blood, vol. 100, no. 6, pp. 2071-2076, 2002.

[16] Platelet Receptor Inhibition in Ischemic Syndrome Management (PRISM) Study Investigators, "A comparison of aspirin plus tirofiban with aspirin plus heparin for unstable angina," New England Journal of Medicine, vol. 338, no. 21, pp. 1498-1505, 1998.

[17] J. E. Tcheng, D. J. Kereiakes, A. M. Lincoff et al., “Abciximab readministration: results of the ReoPro readministration registry," Circulation, vol. 104, no. 8, pp. 870-875, 2001.

[18] S. Lajus, G. Clofent-Sanchez, C. Jais, P. Coste, P. Nurden, and A. Nurden, "Thrombocytopenia after abciximab use results from different mechanisms," Thrombosis and Haemostasis, vol. 103, no. 3, pp. 651-661, 2010.

[19] H. Dasgupta, J. C. Blankenship, G. C. Wood, C. M. Frey, S. L. Demko, and F. J. Menapace, "Thrombocytopenia complicating treatment with intravenous glycoprotein IIb/ IIIa receptor inhibitors: a pooled analysis," American Heart Journal, vol. 140, no. 2, pp. 206-211, 2000.

[20] J. Llevadot, S. A. Coulter, and R. P. Giugliano, "A practical approach to the diagnosis and management of thrombocytopenia associated with glycoprotein IIb/IIIa receptor inhibitors," Journal of Thrombosis and Thrombolysis, vol. 9, no. 2, pp. 175-180, 2000.

[21] L. M. Huxtable, M. J. Tafreshi, and A. N. Rakkar, "Frequency and management of thrombocytopenia with the glycoprotein IIb/IIIa receptor antagonists," American Journal of Cardiology, vol. 97, no. 3, pp. 426-429, 2006.

[22] S. D. Berkowitz, R. A. Harrington, M. M. Rund, and J. E. Tcheng, "Acute profound thrombocytopenia after C7E3 Fab (abciximab) therapy," Circulation, vol. 95, no. 4, pp. 809-813, 1997.

[23] S. D. Berkowitz, D. C. Sane, K. N. Sigmon et al., "Occurrence and clinical significance of thrombocytopenia in a population undergoing high-risk percutaneous coronary revascularization. Evaluation of $\mathrm{c7E} 3$ for the prevention of ischemic complications (EPIC) study group," Journal of the American College of Cardiology, vol. 32, no. 2, pp. 311-319, 1998.

[24] P. A. Merlini, M. Rossi, A. Menozzi et al., "Thrombocytopenia caused by abciximab or tirofiban and its association with clinical outcome in patients undergoing coronary stenting," Circulation, vol. 109, no. 18, pp. 2203-2206, 2004.
[25] D. C. Sane, L. V. Damaraju, E. J. Topol et al., "Occurrence and clinical significance of pseudothrombocytopenia during abciximab therapy," Journal of the American College of Cardiology, vol. 36, no. 1, pp. 75-83, 2000.

[26] C. Gao, B. Boylan, D. Bougie et al., "Eptifibatide-induced thrombocytopenia and thrombosis in humans require FcgammaRIIa and the integrin beta3 cytoplasmic domain," Journal of Clinical Investigation, vol. 119, no. 3, pp. 504-511, 2009.

[27] R. H. Aster, B. R. Curtis, J. G. McFarland, and D. W. Bougie, "Drug-induced immune thrombocytopenia: pathogenesis, diagnosis, and management," Journal of Thrombosis and Haemostasis, vol. 7, no. 6, pp. 911-918, 2009.

[28] D. M. Arnold, I. Nazi, T. E. Warkentin et al., "Approach to the diagnosis and management of drug-induced immune thrombocytopenia," Transfusion Medicine Reviews, vol. 27, no. 3, pp. 137-145, 2013.

[29] D. M. Arnold, S. Kukaswadia, I. Nazi et al., "A systematic evaluation of laboratory testing for drug-induced immune thrombocytopenia," Journal of Thrombosis and Haemostasis, vol. 11, no. 1, pp. 169-176, 2013.

[30] D. W. Bougie, P. R. Wilker, and R. H. Aster, "Patients with quinine-induced immune thrombocytopenia have both "drug-dependent" and "drug-specific" antibodies," Blood, vol. 108, no. 3, pp. 922-927, 2006.

[31] J. Zhu, J. Zhu, D. W. Bougie, R. H. Aster, and T. A. Springer, "Structural basis for quinine-dependent antibody binding to platelet integrinaIIbß3,” Blood, vol. 126, no. 18, pp. 2138-2145, 2015.

[32] D. W. Bougie, J. Peterson, M. Rasmussen, and R. H. Aster, "Mechanism of quinine-dependent monoclonal antibody binding to platelet glycoprotein IIb/IIIa," Blood, vol. 126, no. 18, pp. 2146-2152, 2015.

[33] R. H. Aster and D. W. Bougie, "Drug-induced immune thrombocytopenia," New England Journal of Medicine, vol. 357, no. 6, pp. 580-587, 2007.

[34] J. T. Billheimer, I. B. Dicker, R. Wynn et al., "Evidence that thrombocytopenia observed in humans treated with orally bioavailable glycoprotein IIb/IIIa antagonists is immune mediated," Blood, vol. 99, no. 10, pp. 3540-3546, 2002.

[35] J. A. Peterson, T. N. Nelson, A. J. Kanack, and R. H. Aster, "Fine specificity of drug-dependent antibodies reactive with a restricted domain of platelet GP IIIa," Blood, vol. 111, no. 3, pp. 1234-1239, 2008.

[36] D. W. Bougie, M. Rasmussen, J. Zhu, and R. H. Aster, "Antibodies causing thrombocytopenia in patients treated with RGD-mimetic platelet inhibitors recognize ligandspecific conformers of $\alpha \mathrm{IIb} / ß 3$ integrin," Blood, vol. 119, no. 26, pp. 6317-6325, 2012.

[37] J. N. George, G. E. Raskob, S. R. Shah et al., "Drug-induced thrombocytopenia: a systematic review of published case reports," Annals of Internal Medicine, vol. 129, no. 11, p. 886, 1998.

[38] U. Pedersen-Bjergaard, M. Andersen, and P. B. Hansen, "Drug-induced thrombocytopenia: clinical data on 309 cases and the effect of corticosteroid therapy," European Journal of Clinical Pharmacology, vol. 52, no. 3, pp. 183-189, 1997.

[39] T. A. Rousan, I. T. Aldoss, B. D. Cowley Jr. et al., "Recurrent acute thrombocytopenia in the hospitalized patient: sepsis, DIC, HIT, or antibiotic-induced thrombocytopenia," American Journal of Hematology, vol. 85, no. 1, p. 71, 2010.

[40] M. Yurtdas, Y. T. Yaylali, N. Aladag, M. Ozdemir, and M. H. Atay, "Acute serious thrombocytopenia associated with intracoronary tirofiban use for primary angioplasty," Case 
Reports in Medicine, vol. 2014, Article ID 190149, 3 pages, 2014.

[41] D. Dursunoglu, O. Taskoylu, S. Gür, and I. Sari, “Tirofibaninduced acute profound thrombocytopenia after primary angioplasty," Asian Cardiovascular and Thoracic Annals, vol. 21, no. 1, pp. 74-76, 2013.

[42] J. R. Christen, C. Soubrier, E. Martinez et al., "Long-lasting thrombocytopenia induced by glycoprotein IIb/IIIa inhibitor," La Revue de Médecine Interne, vol. 38, no. 11, pp. 769-773, 2017.

[43] P. Panduranga and K. Sulaiman, "Severe thrombocytopenia following tirofiban infusion," Indian Journal of Pharmacology, vol. 43 , no. 6, pp. 726-728, 2011.

[44] E. Garbe, F. Andersohn, E. Bronder et al., "Drug-induced immune thrombocytopaenia: results from the berlin casecontrol surveillance study," European Journal of Clinical Pharmacology, vol. 68, no. 5, pp. 821-832, 2012.

[45] N. Rahman and F. H. Jafary, "Vanishing platelets: rapid and extreme tirofiban-induced thrombocytopenia after percutaneous coronary intervention for acute myocardial infarction," Texas Heart Institute Journal, vol. 37, no. 1, pp. 109-112, 2010.

[46] J. N. George and R. H. Aster, "Drug-induced thrombocytopenia: pathogenesis, evaluation, and management," Hematology, vol. 2009, no. 1, pp. 153-158, 2009.

[47] T. Golden, S. Ghazala, R. Wadeea, and S. Junna, "Abciximab-induced acute profound thrombocytopenia postpercutaneous coronary intervention," BMJ Case Report, pii: bcr-2017-221182, 2017.

[48] B. Álvarez-Camarena, E. Frutos-Rangel, E. Rico-Curiel, J. M. García-y Otero, and E. Frutos-Rodríguez, "Acute profound thrombocytopenia associated with the use of abciximab: case report," Archivos De Cardiologia De Mexico, vol. 81, no. 4, pp. 317-321, 2011.

[49] C. Graidis, C. Golias, D. Dimitriadis et al., "Eptifibatideinduced acute profound thrombocytopenia: a case report," BMC Research Notes, vol. 7, no. 1, p. 107, 2014.

[50] O. C. Elcioglu, A. Ozkok, T. S. Akpinar et al., "Severe thrombocytopenia and alveolar hemorrhage represent two types of bleeding tendency during tirofiban treatment: case report and literature review," International Journal of Hematology, vol. 96, no. 3, pp. 370-375, 2012. 


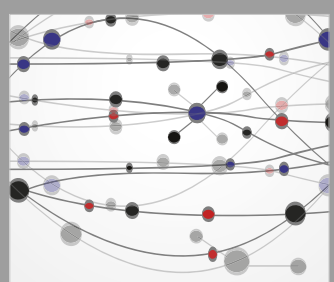

The Scientific World Journal
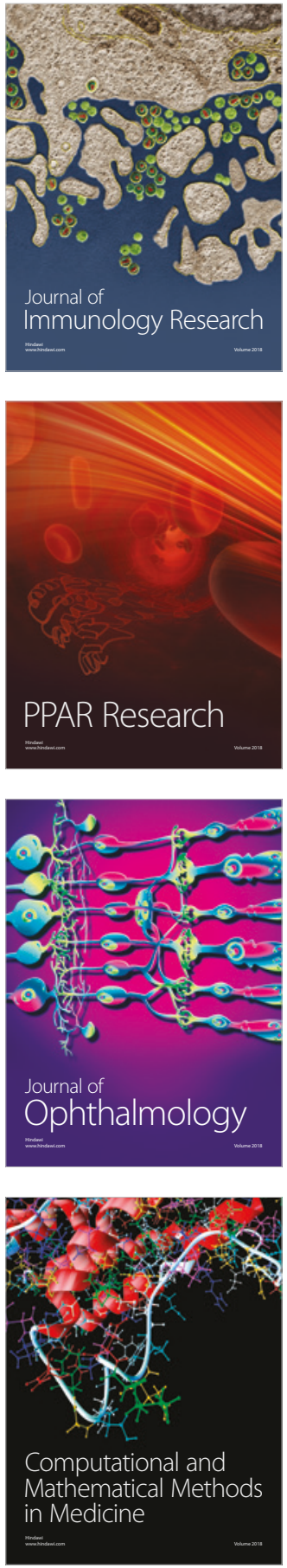

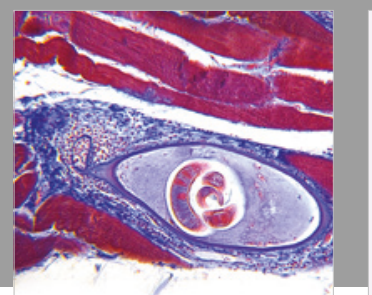

Gastroenterology Research and Practice

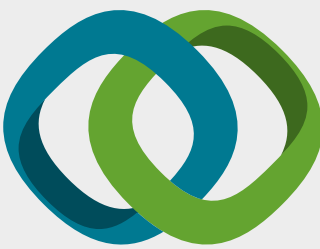

\section{Hindawi}

Submit your manuscripts at

www.hindawi.com
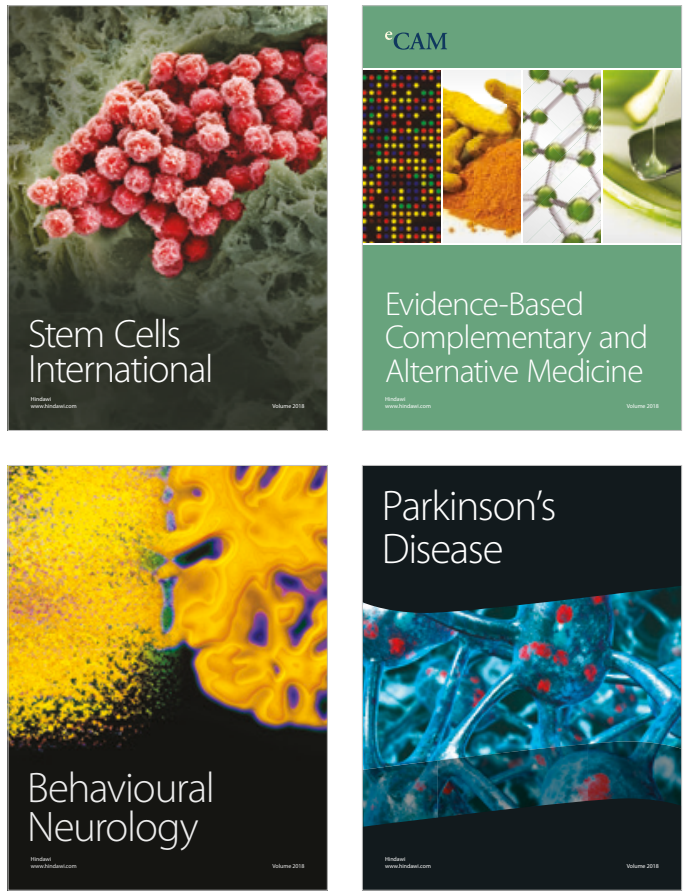

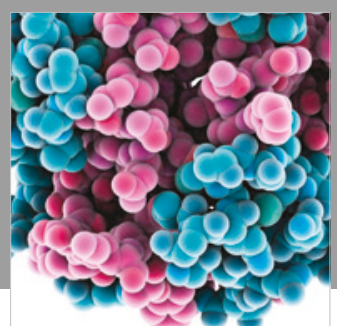

ournal of

Diabetes Research

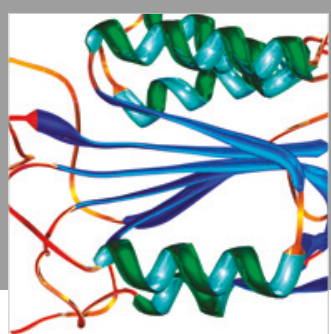

Disease Markers
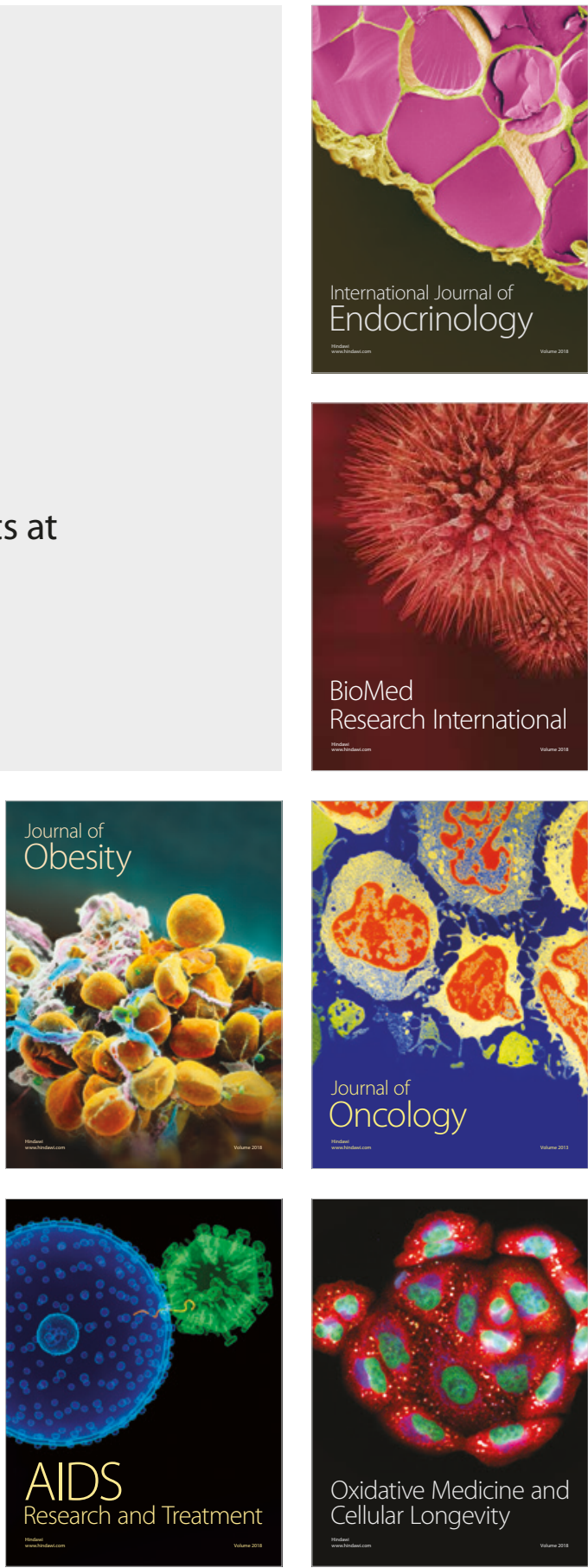